Article

\title{
Demonstration Plant Equipment Design and Scale-Up from Pilot Plant of a Leaching and Solvent Extraction Process
}

\section{Fátima Arroyo *, Constantino Fernández-Pereira and Pilar Bermejo}

School of Engineering, Chemical and Environmental Engineering Department, University of Seville, Camino de los Descubrimientos, Seville 41092, Spain; E-Mails: Pereira@etsi.us.es (C.F.-P.); pbermoz@gmail.com (P.B.)

* Author to whom correspondence should be addressed; E-Mail: fatimarroyo@etsi.us.es; Tel.: +34-954-482-274; Fax: +34-954-486-082.

Academic Editor: Anna H. Kaksonen

Received: 13 February 2015 / Accepted: 19 May 2015 / Published: 28 May 2015

\begin{abstract}
Germanium recovery from coal fly ash by hydrometallurgical procedures was studied at the pilot scale ( $5 \mathrm{~kg}$ of fly ash $/ \mathrm{h}$ ). Results were used to design the equipment of a demonstration-sized plant (200 kg of fly ash/h). The process is based on hydrometallurgical operations: firstly a germanium extraction from fly ash by leaching and a consequent $\mathrm{Ge}$ separation from the other elements present in the solution by solvent extraction procedures. Based on the experimental results, mass balances and McCabe-Thiele diagrams were applied to determine the number of steps of the solvent extraction stage. Different arrangements have been studied and a countercurrent process with three steps in extraction and six steps in elution was defined. A residence time of 5 min was fixed in both the extraction and elution stages. Volumetric ratios in extraction and stripping were: aqueous phase/organic phase $=5$ and organic phase/stripping phase $=5$, so a concentration factor of 25 is achieved. Mixers and decanters were completely defined. The maximum extracted and eluted germanium was estimated and a global efficiency of $94 \%$ was achieved. The cost-effectiveness of the equipment was estimated using the Lang factors.
\end{abstract}

Keywords: germanium; fly ash; pilot plant; design; scale up; hydrometallurgy 


\section{Introduction}

Germanium is not very abundant in the Earth's crust, occurring only at a concentration of 1 to $7 \mathrm{ppm}$ [1]. It is widely dispersed in nature, sometimes as a pure metal in association with more abundant elements (such as $\mathrm{Zn}$ and its minerals) and as germanium oxide. By far, the most important application of germanium is in the manufacturing of semiconductors, but innovative uses for germanium in new and high technological industrial applications have led to an increase in its price, so it is currently more attractive to process raw materials with low contents of germanium (sometimes only a few ppm) and considerable quantities of other elements.

Worldwide, about $30 \%$ of the total germanium consumed comes from recycled materials. With regard to "new" germanium production, the main sources are the zinc and copper ores, from which germanium is obtained as a byproduct. Nevertheless, due to the uses for germanium in new and high technological industrial applications, germanium metal and oxide have increased in price (1800 \$/kg of germanium metal in September 2013) [2], and alternative sources such as combustion [3] and gasification [4] coal fly ashes. When the coal is gasified under proper conditions the fly ash (FA) can reach germanium contents ten times higher than the germanium content in the original coal [5].

Fly ash valorization poses a significant economic and environmental burden, but can also be viewed as a resource of huge potential. There are a few approaches nowadays for FA valorization aside from building purposes since it has a potential role as a value-added product in material preparation (e.g., ceramics), recovery of materials (e.g., metals) and agricultural applications (e.g., as bioremediation). Nevertheless, in most cases, reported work to date in this area has been of theoretical research or laboratory scale and further development work is needed.

Germanium occurs in relatively high contents in the fly ash (FA) produced in the Puertollano (Spain) Integrated Gasification Combined Cycle (IGCC) power plant. Nowadays, the $335 \mathrm{MW}$ (ISO) Puertollano IGCC plant is the largest worldwide gasification plant in operation. In this plant, a 50:50 local coal/pet-coke blend is gasified with $2 \%-4 \% \mathrm{w} / \mathrm{w}$ of limestone (fluxing agent), in a pressurized entrained flow gasifier, at $1600{ }^{\circ} \mathrm{C}$ and 25 bars. The Puertollano coal is a high volatile bituminous coal, rich in a number of metals [6], while pet-coke, supplied by an oil refinery is generally a C-rich material with high concentrations of $\mathrm{S}, \mathrm{V}$ and $\mathrm{Ni}$ [7]. The high slag/FA ratio (90:10 or 85:15) produced in the Puertollano IGCC plant is the opposite with respect to that of conventional pulverized coal combustion plants (20:80). Germanium is completely volatilized during gasification and subsequently condenses during gas cooling to form sulphides and oxide species [8]. The complete volatilization of these elements is caused by the organic occurrence of $\mathrm{Ge}$ and the main sulphide affinity of $\mathrm{Pb}, \mathrm{Ga}$ and $\mathrm{Bi}$ in the Puertollano coal [8]. The high calcophile affinity of these elements in reducing conditions account for the formation of sulphide species, such as galena for $\mathrm{Pb}, \mathrm{GeS}$ and $\mathrm{GeS}_{2}$ for $\mathrm{Ge}$ or substituting for $\mathrm{Zn}$ in spharelite/wurtzite lattices for $\mathrm{Ga}$, and the subsequent high retention of these elements in fly ash [8] (Table 1).

Germanium occurs in FA mainly (up to $91 \% \mathrm{w} / \mathrm{w}$ ) as water-soluble hexagonal- $\mathrm{GeO}_{2}$ and $\mathrm{GeS}_{2}$ (solubility: $4.5 \mathrm{~g} / \mathrm{L}$ ) and GeS (solubility: $2.4 \mathrm{~g} / \mathrm{L}$ ). Minor proportions (up to $20 \%$ ) of Ge may occur as low soluble species (tetragonal- $\mathrm{GeO}_{2}$ or $\mathrm{GeO}_{4}$ tetrahedral).

Many conventional techniques have been developed to separate germanium from other elements contained in leachates, including precipitation with tannin, distillation of $\mathrm{GeCl}_{4}$ [9], flotation of a $\mathrm{Ge}$ 
complex [10,11] adsorption onto activated carbon [12], precipitation [13], solvent extraction [14,15] and sorption onto chelating exchange resins $[16,17]$.

Table 1. Production date, limestone dosage (\%), coal/pet-coke ratio and Ge content $(\mathrm{mg} / \mathrm{kg})$ in fly ash samples selected for Ge and Ga extraction tests [8].

\begin{tabular}{ccccc}
\hline Fly Ash & Date & Limestone (\%) & Coal/Pet-Coke Dose & Ge Content $(\mathbf{m g} / \mathbf{k g})$ \\
\hline FA\#2 & $11 / 09 / 1999$ & 4.1 & $50: 50$ & 347 \\
FA\#7 & $24 / 10 / 2000$ & 2.6 & $50: 50$ & 244 \\
FA\#10 & $--/ 11 / 2002$ & 2.2 & $50: 50$ & 356 \\
FA\#13 & $20 / 10 / 2005$ & 2.5 & $50: 50$ & 319 \\
FA\#15 & $03 / 06 / 2008$ & 2.7 & $50: 50$ & 235 \\
FA\#16 & $30 / 06 / 2008$ & 2.8 & $50: 50$ & 268 \\
FA\#17 & $02 / 07 / 2008$ & 2.8 & $50: 50$ & 228 \\
FA\#18 & $19 / 09 / 2008$ & 2.4 & $50: 50$ & 174 \\
\hline
\end{tabular}

The solvent extraction (SX) method for the recovery of germanium from fly ash is based on the germanium-1, 2-dihydroxybenzene (catechol, CAT) $\left(\mathrm{C}_{6} \mathrm{O}_{2} \mathrm{H}_{6}\right)$ chelate and the subsequent extraction of the complex using tri-n-octylamine (TOA) $\left(\left(\mathrm{C}_{8} \mathrm{H}_{17}\right)_{3} \mathrm{~N}\right)$ and stripping with alkaline solutions. The equilibrium extraction and stripping are given by the following equations respectively:

$$
2\left(\mathrm{C}_{8} \mathrm{H}_{17}\right)_{3} \mathrm{~N}_{(\text {org })}+\mathrm{Ge}(\mathrm{OH})_{4(\mathrm{aq})}^{\mathrm{o}}+3\left(\mathrm{C}_{6} \mathrm{O}_{2} \mathrm{H}_{6}\right)_{(\text {aq })} \rightarrow\left(\left(\mathrm{C}_{8} \mathrm{H}_{17}\right)_{3} \mathrm{NH}\right)_{2} \mathrm{Ge}\left(\mathrm{C}_{6} \mathrm{O}_{2} \mathrm{H}_{4}\right)_{3(\text { org })}+4 \mathrm{H}_{2} \mathrm{O}
$$

Once the Ge is in the organic phase, two stripping possibilities are apparently possible, because the ternary complex is not stable in strong acidic or alkaline solutions [18]. Alkaline stripping is shown in Equation (2).

$$
\left(\left(\mathrm{C}_{8} \mathrm{H}_{17}\right)_{3} \mathrm{NH}\right)_{2} \mathrm{Ge}\left(\mathrm{C}_{6} \mathrm{O}_{2} \mathrm{H}_{4}\right)_{3(\text { org })}+2 \mathrm{OH}^{-}{ }_{(\text {aq })} \rightarrow 2\left(\mathrm{C}_{8} \mathrm{H}_{17}\right)_{3} \mathrm{~N}_{(\text {org })}+\mathrm{Ge}\left(\mathrm{C}_{6} \mathrm{O}_{2} \mathrm{H}_{6}\right)_{3(\text { (aq) }}+2 \mathrm{H}_{2} \mathrm{O}
$$

The last step of a hydrometallurgy process for the recovery of germanium from FA consisted in precipitation processes for germanium from the Ge-bearing solutions. A possible precipitation is based on precipitating Ge with cetyltrimethylammonium bromide (CTAB) and catechol [19]. The Ge-CAT complex has a high solubility in water probably due to its polarity, but when CTAB is added to an aqueous solution that contains the Ge-CAT complex, the $\mathrm{CTA}^{+}$cation and the Ge-CAT complex form a heavy ion pair that precipitates. The ion-pair could be formed as follows if the stoichiometric ratio of reagents is Ge:CAT:CTAB 1:3:2 [19,20].

$$
2 \mathrm{C}_{19} \mathrm{H}_{42} \mathrm{NBr}+\left[\mathrm{Ge}\left(\mathrm{C}_{6} \mathrm{H}_{4} \mathrm{O}_{2}\right)_{3}\right]^{2-} \rightarrow\left(\mathrm{C}_{19} \mathrm{H}_{42} \mathrm{~N}\right)_{2} \mathrm{Ge}\left(\mathrm{C}_{6} \mathrm{H}_{4} \mathrm{O}_{2}\right)_{3}+2 \mathrm{Br}^{+}
$$

The Ge precipitate can be roasted (at temperature $>600{ }^{\circ} \mathrm{C}$ ) rendering an end product in the form of germanium dioxide. The mechanism for the decomposition of the germanium-complex has been published previously [19,20].

A pilot plant operation is usually needed to generate information about the behavior of the system to be used in the design of larger facilities; therefore, a pilot plant was designed to test this hydrometallurgical method and to obtain operating conditions and some data necessary for a future larger plant design. The main points related to equipment design of the pilot plant were continuity and versatility [20], taking into account the scaling up from the pilot scale to a demonstration level. 
This paper shows the design of a demonstration plant from experiments carried out at the pilot scale regarding leaching and SX process.

\section{Process and Pilot Plant}

The pilot plant design was based on the results obtained at laboratory scale $[13,14,21]$ and it was operated in a continuous mode. A schematic arrangement of the flow configuration is illustrated in Figure 1, and pilot plant design and experimentation have been previously published [22]. The pilot plant comprised two main stages: germanium extraction from FA (leaching with water) and separation of germanium from other elements dissolved in the leachate (L) (interferences). After water leaching, wet fly ash and leachate are separated in a vacuum filter. Catechol is added to leachate and the pregnant solution (leachate $+\mathrm{CAT}+\mathrm{H}_{2} \mathrm{SO}_{4}$ ) is contacted in a mixer-settler unit with an organic phase carrying an extracting agent for Ge. After extraction, the aqueous phase (AP) and organic phase (OP) are allowed to separate in the settler. The organic solution from the extraction stage feeds the stripping mixer-settler where it is contacted with an alkaline stripping solution (SP), which reverses the extraction process.

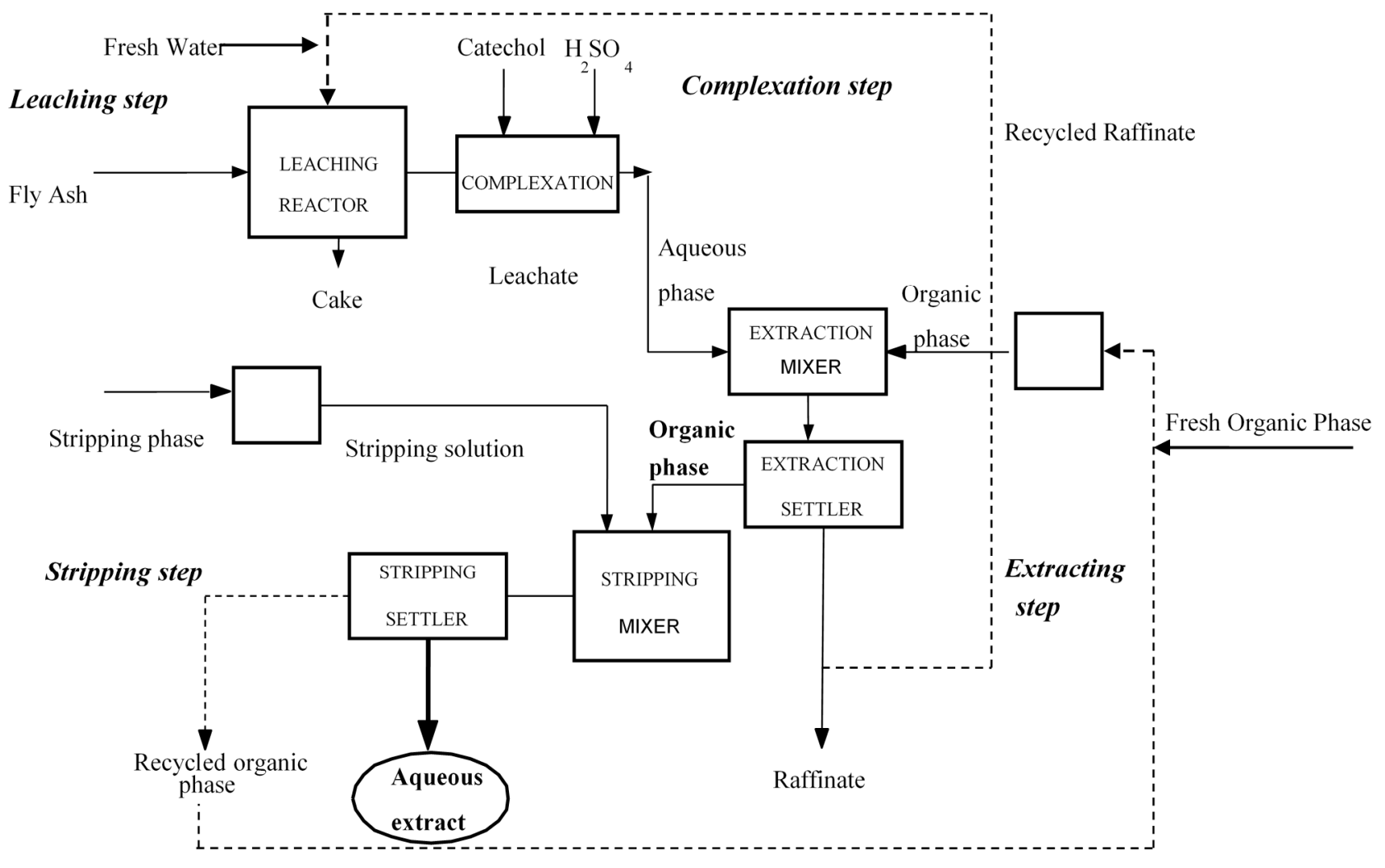

Figure 1. Pilot plant flow sheet scheme.

The pilot plant mass balance was performed with a feedstock of $5 \mathrm{~kg} / \mathrm{h}$ of fly ash, with a theoretical recovery of germanium of $1.3 \mathrm{~g} / \mathrm{h}\left(\right.$ as $\left.\mathrm{GeO}_{2}\right)$ [22].

The pilot plant is fed with $5 \mathrm{~kg} / \mathrm{h}$ of FA and it consists of a leaching reactor unit $(100 \mathrm{~L})$, a complex formation tank $(30 \mathrm{~L})$, two mixer-settler units, for extraction (mixer: $10 \mathrm{~L}$-settler: $2 \mathrm{~L}$ with $120 \mathrm{~cm}^{2}$ of settling area) and stripping (mixer: $3.5 \mathrm{~L}$ - settler: $0.8 \mathrm{~L}$ with $100 \mathrm{~cm}^{2}$ of settling area) three auxiliary reactors for raffinate discharge and storage $(30 \mathrm{~L})$, organic phase preparation $(25 \mathrm{~L})$ and germanium-rich 
final solution storage (10 L), all constructed of stainless steel. Auxiliary dosifiers, tanks, pumps, valves and control devices were also integrated into the process [22].

One fundamental stage of the process was the germanium leaching performed in a reactor with water and FA continuous additions. Some leaching tests with three different $\mathrm{L} / \mathrm{S}$ ratios $(3,5$ and 7$)$ were carried out at laboratory and pilot plant scale $[13,14]$. At leaching times $<6 \mathrm{~h}$, a small increase of germanium extraction was observed with increasing $\mathrm{L} / \mathrm{S}$ ratio. But taking into account other aspects such as the fluency of the fly ash-water mixture, worse for $\mathrm{L} / \mathrm{S}=3$, or the quantity of liquid residues, higher in the case of $\mathrm{L} / \mathrm{S}=7$, tests performed in the pilot plant confirmed $\mathrm{L} / \mathrm{S}=5$ as the optimum relation in agreement with the laboratory results $[13,14]$. After the leaching, wet FA and leachate were separated by a vacuum rotary filter [22]. Concerning the SX method, previous results show that the extraction yields achieve $95 \%$ after 5 min of residence time when AP/OP $=5$ is used [13,14]. Regarding the stripping stage, the germanium stripping yields achieve $98 \%$ with a sodium hydroxide solution in 5 min (residence time) for $\mathrm{OP} / \mathrm{SP}=5[13,14]$.

The reutilization of raffinate as leaching solution was studied, and results show the best option in terms of leaching yield. Tests were performed and results are shown in Table 2. A larger amount of raffinate in the leaching solution increased the germanium content in leachate, but if the $\mathrm{pH}$ of the leaching solution is very low, the puzzolanity of the fly ash can change, avoiding its reutilization after germanium extraction in many of their current applications [4,21]. Fly ash would also be a residue instead of a by-product so a leaching solution constituted by $75 \%$ of raffinate from SX process and $25 \%$ of fresh water (Table 2) was selected. With this reutilization, the Ge extraction yield can increase up to $25 \%$ compared with the leaching with water due to the low $\mathrm{pH}$ and the amount of catechol, so leachates with Ge contents of $50 \mathrm{mg} / \mathrm{L}$ can be achieved. Residence time decreased due to catechol and acid effect to $2 \mathrm{~h}$ (from $24 \mathrm{~h}$ with water leaching).

Table 2. Leaching tests with different raffinate/water ratios and residence times.

\begin{tabular}{ccc}
\hline Leaching Solution & Leaching Time (h) & Ge in Leachate (mg/L) \\
\hline \multirow{2}{*}{$65 \%$ raffinate } & 1.5 & 30 \\
$35 \%$ water & 2 & 45 \\
& 6 & 40 \\
\hline \multirow{2}{*}{$75 \%$ raffinate } & 1.5 & 32 \\
$25 \%$ water & 2 & 53 \\
& 6 & 46 \\
\hline \multirow{2}{*}{$85 \%$ raffinate } & 1.5 & 43 \\
$15 \%$ water & 2 & 52 \\
& 6 & 49 \\
\hline
\end{tabular}

The return of the organic phase in the SX stage was also studied in the pilot plant trials and results shown that TOA remained in the OP after stripping, so reutilization of OP is possible and extraction yields remained almost constant [21]. Some fresh organic phase diluent and TOA has to be introduced in the system due to evaporation and entrainments in the raffinate losses. 


\section{Preliminary Mass Balance}

The actual FA production of ELCOGAS IGCC Power Plant (Puertollano, Spain) is $2000 \mathrm{~kg} / \mathrm{h}$. The demonstration plant was designed for $10 \%$ of actual FA production because, for a new process, a conservative scaling factor of 10 is recommended by some authors [23]. The design considered a demonstration plant capacity of $200 \mathrm{~kg} / \mathrm{h}$ fly ash $(10 \%$ of $2000 \mathrm{~kg} / \mathrm{h})$ with a Ge content of $300-400 \mathrm{ppm}$ (Table 1). In Table 3, the pilot plant and demonstration plant preliminary mass balances are shown.

Table 3. Pilot plant and demonstration plant preliminary mass balance. Ge mass balance.

\begin{tabular}{|c|c|c|c|c|c|c|c|}
\hline \multicolumn{2}{|c|}{ Main Compounds } & \multirow{2}{*}{$\begin{array}{c}\text { Flow } \\
5.0 \\
\end{array}$} & \multirow{2}{*}{$\begin{array}{l}\text { Units } \\
\mathrm{kg} / \mathrm{h} \\
\end{array}$} & \multirow{2}{*}{$\begin{array}{c}\text { Concentration }(\mathbf{m g} / \mathbf{L}) \\
350\end{array}$} & \multirow{2}{*}{$\begin{array}{c}\text { Flow } \\
200 \\
\end{array}$} & \multirow{2}{*}{$\begin{array}{l}\text { Units } \\
\mathrm{kg} / \mathrm{h} \\
\end{array}$} & \multirow{2}{*}{$\begin{array}{c}\text { Ge Total (g) } \\
70.0 \\
\end{array}$} \\
\hline Fly ash & FA & & & & & & \\
\hline \multirow{3}{*}{ Leaching solution $(\mathrm{W} / \mathrm{FA}=5)$} & Fresh water $(\mathrm{FW})$ & 6.3 & $\mathrm{~L} / \mathrm{h}$ & 0 & 250 & $\mathrm{~L} / \mathrm{h}$ & 0.0 \\
\hline & $\mathrm{R}$ recycled (RR) & 18.8 & $\mathrm{~L} / \mathrm{h}$ & 4 & 750 & $\mathrm{~L} / \mathrm{h}$ & 3.0 \\
\hline & Total & 25.0 & $\mathrm{~L} / \mathrm{h}$ & - & 1000 & $\mathrm{~L} / \mathrm{h}$ & 3.0 \\
\hline Leachate/Aqueous phase & AP & 22.4 & $\mathrm{~L} / \mathrm{h}$ & 53 & 896 & $\mathrm{~L} / \mathrm{h}$ & 46.8 \\
\hline \multirow{3}{*}{ Cake } & $\mathrm{C}(\mathrm{FA})$ & 5.0 & $\mathrm{~kg} / \mathrm{h}$ & - & 200 & $\mathrm{~kg} / \mathrm{h}$ & 20.7 \\
\hline & C (leachate) & 2.6 & $\mathrm{~L} / \mathrm{h}$ & 53 & 104 & $\mathrm{~L} / \mathrm{h}$ & 5.5 \\
\hline & Total (Wet FA) & 7.5 & - & - & 300 & - & 26.2 \\
\hline \multirow{3}{*}{$\begin{array}{l}\text { Organic phase } \\
(\mathrm{AP} / \mathrm{OP}=5)\end{array}$} & Fresh OP (FOP) & 0.4 & $\mathrm{~L} / \mathrm{h}$ & 0 & 17.9 & $\mathrm{~L} / \mathrm{h}$ & 0.0 \\
\hline & ROP (recycled) & 4.0 & $\mathrm{~L} / \mathrm{h}$ & 20 & 161.3 & $\mathrm{~L} / \mathrm{h}$ & 3.2 \\
\hline & Total & 4.5 & $\mathrm{~L} / \mathrm{h}$ & - & 179.2 & $\mathrm{~L} / \mathrm{h}$ & 3.2 \\
\hline \multirow{3}{*}{ Organic extract } & $\mathrm{OE}$ & 4.3 & $\mathrm{~L} / \mathrm{h}$ & 259 & 170.2 & $\mathrm{~L} / \mathrm{h}$ & 44.0 \\
\hline & Losses & 0.2 & $\mathrm{~L} / \mathrm{h}$ & 259 & 9.0 & $\mathrm{~L} / \mathrm{h}$ & 2.4 \\
\hline & Total & 4.5 & $\mathrm{~L} / \mathrm{h}$ & - & 180 & $\mathrm{~L} / \mathrm{h}$ & - \\
\hline \multirow{3}{*}{ Raffinate } & Residual raffinate & 3.7 & $\mathrm{~L} / \mathrm{h}$ & 4 & 146 & $\mathrm{~L} / \mathrm{h}$ & 0.6 \\
\hline & For recycling (RR) & 18.8 & $\mathrm{~L} / \mathrm{h}$ & 4 & 750 & $\mathrm{~L} / \mathrm{h}$ & 3.0 \\
\hline & Total Raffinate & 22.4 & $\mathrm{~L} / \mathrm{h}$ & 4 & 896 & $\mathrm{~L} / \mathrm{h}$ & 3.6 \\
\hline Stripping phase $(\mathrm{OE} / \mathrm{SP}=5)$ & SP & 0.9 & $\mathrm{~L} / \mathrm{h}$ & 0 & 34.0 & $\mathrm{~L} / \mathrm{h}$ & 0.0 \\
\hline Aqueous extract & $\mathrm{AE}$ & 0.9 & $\mathrm{~L} / \mathrm{h}$ & 1243.2 & 34.0 & $\mathrm{~L} / \mathrm{h}$ & 42.3 \\
\hline \multirow{2}{*}{ Residual organic phase } & ROP & 4.0 & $\mathrm{~L} / \mathrm{h}$ & 20 & 161.3 & $\mathrm{~L} / \mathrm{h}$ & 3.2 \\
\hline & Losses & 0.2 & $\mathrm{~L} / \mathrm{h}$ & 20 & 9.0 & $\mathrm{~L} / \mathrm{h}$ & 0.2 \\
\hline
\end{tabular}

A total of $83.9 \%$ of recovered raffinate was reintroduced in the process as leaching agent, and $95 \%$ of the organic phase was reintroduced in the process too.

A germanium balance is included, and $61 \mathrm{~g} / \mathrm{h}$ of $\mathrm{GeO}_{2}$ (equivalent) could be recovered from the $200 \mathrm{~kg} / \mathrm{h}$ of FA.

\section{Demonstration Equipment Design}

In the case of the demonstration plant, geometric similitude with pilot plant equipment was maintained. The criteria for the pilot plant equipment design was the simplest as possible, because a hydrometallurgical process for a residue valorization (with a low content of germanium) only can be profitable if both equipment and operational costs are low. 


\subsection{Leaching Equipment}

Leaching solution comes into contact with the coal fly ash in the leaching reactor to dissolve the germanium content. The leaching reactor is a stirred tank, and the basic design parameters are: geometry, construction material, design and location of baffles and, design of agitator [24].

Maintaining the pilot plant equipment geometry, the leaching reactor is made up of vertical cylindrical jacketed stainless steel AISI 316 vessel with a tori-spherical bottom and up heads and a central agitator to avoid vortex. It is an up charging reactor with a bottom discharge valve (Figure 2).
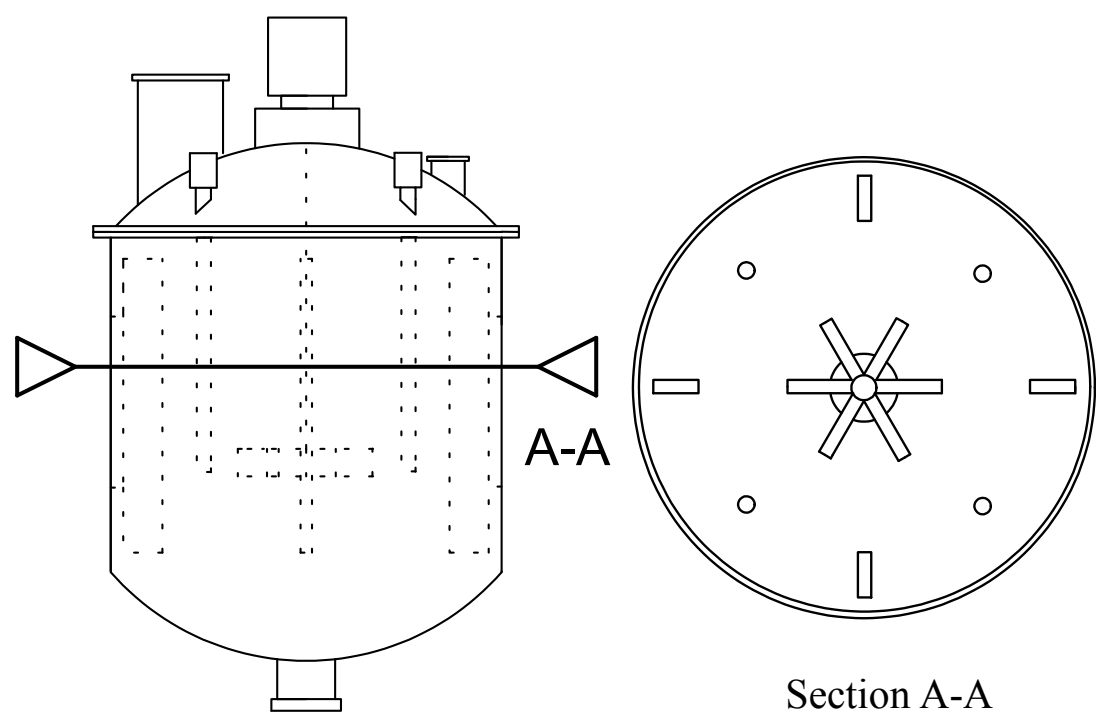

Section A-A

Figure 2. Leaching reactor scheme.

Accordingly with the mass balance (Table 2) $1000 \mathrm{~L} / \mathrm{h}$ of water/leachate and $200 \mathrm{~kg} / \mathrm{h}$ of fly ash are discharged. If the residence time is $2 \mathrm{~h}$ and a filling factor of $80 \%$ was selected, the required volume of the leaching reactor is $2.73 \mathrm{~m}^{3}$. The volume is defined as the sum of the cylindrical volume and the volume of the heads (Equation (4)).

$$
V_{\text {reactor }}=V_{\text {cylinder }}+2 \cdot V_{\text {head }}=\frac{\pi}{4} \cdot D^{2} \cdot H+2 \cdot 0.0809 \cdot D^{3}
$$

Where $V_{\text {reactor }}$ is the volume of the reactor, $V_{\text {cylinder }}$ is the volume of the cylindrical part, $V_{\text {head }}$ is the volume of the tori-spherical bottom and head of the reactor, and $D$ and $H$ are the reactor diameter and height respectively. For agitated reactors, a diameter similar to height is preferred [25], so the diameter and height of the leaching reactor have been determined as 1450 and $1400 \mathrm{~mm}$ respectively (Figure 2).

Stirring tanks should have baffles to prevent the formation of vortices and promote the contact between phases. Baffle shapes depend on the solution viscosity. For the slurry (FA and water) the deflectors are standard and they should maintain determined ratios approximately (Equations (5)-(7)) [25].

$$
\begin{gathered}
b_{w}=\frac{D}{10} \\
b_{c}=0.15 \cdot b_{w}
\end{gathered}
$$




$$
b_{a}=\frac{1}{2} \cdot b_{w}
$$

Where $D$ is the reactor diameter, $b_{w}$ is the baffle width $(150 \mathrm{~mm}), b_{\mathrm{c}}$ is the separation of the baffles from the reactor wall $(23 \mathrm{~mm})$, and $b_{a}$ is the height to which the deflectors are placed over the reactor bottom $(75 \mathrm{~mm})$. Four stainless steel AISI 316 baffles have been distributed along the perimeter of the tank (cross form), and $b_{\mathrm{w}}=150 \mathrm{~mm}, b_{\mathrm{c}}=23 \mathrm{~mm}$ and $b_{\mathrm{a}}=75 \mathrm{~mm}$ were calculated using Equations (6) and (7).

An agitating system is employed to promote the contact between FA and leaching solution. To encourage contact between the two phases, turbine agitators are recommended [25], so turbine agitators with 6 flat $45^{\circ}$ inclined blades were chosen. The recommended geometry of the agitator is related to the reactor geometry (Equations (8)-(10)).

$$
\begin{gathered}
\frac{d_{\text {imp }}}{D}=0.2-0.5 \\
\frac{h_{\text {imp }}}{D}=0.17-0.34 \\
\frac{l_{\text {blades }}}{d_{\text {imp }}}=0.25
\end{gathered}
$$

Where $d_{\text {imp }}$ is the diameter of the impeller, $h_{\text {imp }}$ is the height to which the impeller is placed over the reactor bottom, $l$ blades is the blades length, and $D$ is the reactor diameter. A ratio impeller diameter/reactor diameter of 0.33 was selected since for the mixing of immiscible liquids small impellers at high speeds are recommended [25]. According to previous equations, the geometry of the turbine agitator was $d_{\text {imp }}=525 \mathrm{~mm}, h_{\text {imp }}=380 \mathrm{~mm}$, and $l_{\text {blades }}=93 \mathrm{~mm}$.

The maximum rotational speed $\left(N_{\max }\right)$ of the impeller can be estimated using the Equation (11).

$$
N_{\max }^{3} \cdot d_{\text {imp }}^{2}<20
$$

Where $d_{\text {imp }}$ is the diameter of the impeller. The $N_{\max }$ recommended for this agitator is $110 \mathrm{r} \cdot \mathrm{min}^{-1}$.

For turbine agitators power consumption is usually expressed by the dimensionless Newton number $N_{\mathrm{P}}$ (Equation (12)) and the rotational Reynolds number Re (Equation (13)) when no vortex is present. This procedure provides a single master curve that depends only on impeller geometry and can be used to predict power requirements for any given fluid properties (density $\rho$ and viscosity $\mu$ ), impeller dimensions and rotational speed [26].

$$
\begin{gathered}
N_{F}=\frac{P}{N^{3} \cdot d_{\mathrm{imp}}^{5} \cdot \rho} \\
R e=\frac{N \cdot d_{\mathrm{imp}}^{2} \cdot \rho}{\mu}
\end{gathered}
$$

Where $N_{\mathrm{P}}$ is the Newton (or power) number, $R e$ is the Reynolds number, $d_{\text {imp }}$ is the diameter of the impeller (expressed in $\mathrm{m}), \mu$ is the viscosity of the fluid $(\mathrm{Pa} \cdot \mathrm{s})$ and $\rho$ is the density of the fluid $\left(\mathrm{kg} / \mathrm{m}^{3}\right)$. 
In case of the leaching reactor, for the maximum recommended agitator speed, turbulent regime is achieved ( $R e \approx 25,000)$, so $N_{\mathrm{P}}$ is independent of Re and can be calculated graphically as 2 [25]. The required power is $0.5 \mathrm{~kW}$.

\subsection{Filter}

According to the fly ash physical characteristics (refinement) and pilot plant vacuum filter performance, a filter press has been chosen to separate the fly ash and leachate from leaching reactor. This equipment operates discontinuously, so to maintain the continuity of the industrial plant operation, two press filters have been designed which operate alternately. Both filters are identical.

Equation (14) allows calculation of the needed filtration area. The fabric resistance has been neglected against the cake resistance $[27,28]$.

$$
Q=\frac{A_{F} \cdot \Delta P}{\mu \cdot \alpha \cdot C_{S} \cdot \frac{V_{F}}{A_{F}}}
$$

Where $Q$ is the flow $\left(\mathrm{m}^{3} / \mathrm{h}\right), A_{F}$ is the filtration area $\left(\mathrm{m}^{3}\right), V_{F}$ is the volume of filtrate $\left(\mathrm{m}^{3}\right), \Delta P$ is the pressure drop across the filter $(\mathrm{Pa}), \mu$ is the dynamic viscosity of the fluid $(\mathrm{Pa} \cdot \mathrm{s})$, and $C_{s}$ is the solids concentration.

For the design of filters, it is necessary to establish a filtration time (the time between filling the filter to the time at which proceeds to download the cakes). In this work, a filtration time of $2 \mathrm{~h}$ was proposed taking into account the leaching time $(2 \mathrm{~h})$ to maintain the continuity of the process. At this time, the filter must process a slurry flow rate of $896 \mathrm{~L} / \mathrm{h}$ (with a solids concentration of $183 \mathrm{~kg} / \mathrm{m}^{3}$ ) (Table 2), so the total filtrate volume (in a filtration cycle, it means $2 \mathrm{~h}$ ) is $1792 \mathrm{~L}$.

The maximum pressure drop for a small-medium size filter (plate size $300-1300 \mathrm{~mm}$ ) is 16 bar. This provides the smallest filtering area required. Usually, the batch experiments performed at constant increment de $P$ for determination of filtration parameters, are expressed as a line (Equation $(15))[28,29]$.

$$
\frac{t_{F}}{V_{F}}=\frac{\mu \cdot \alpha \cdot C_{S}}{A_{F}{ }^{2} \cdot \Delta P} V_{F}+\frac{\mu \cdot R m}{A_{F} \cdot \Delta P}=K_{P} \cdot V_{F}+K_{m}
$$

where $t_{F}$ is the filtration time and $V_{F}$ is the cumulative filtrate volume. So, the slope of the line $\left(K_{p}\right)$ was determined from tests in laboratory $\left(1.8 \cdot 10^{10}\right)$. Using the definition of $K_{p}$ (Equation (15)), the specific cake resistance $(\alpha)$ can be calculated:

$$
\begin{aligned}
& K_{p}=\frac{\mu \cdot \alpha \cdot C_{S}}{A_{F}{ }^{2} \cdot \Delta P} \\
& A_{F}=N_{F P} \cdot l_{F P}^{2}
\end{aligned}
$$

Where $l_{F P}$ is the length of filtering plates and $N_{F P}$ is the number of filtering plates. The calculated specific resistance of cake (Equation (16)) was $1.02 \times 10^{12} \mathrm{~m} / \mathrm{kg}$, so the filtering area (Equation (17)) was $5.6 \mathrm{~m}^{2}$. Accordingly to Equations (16) and (17), the designed filtering plate length is $500 \mathrm{~mm}$, and 23 plates are required. 


\subsection{Extraction Equipment}

The fertile solution is contacted with the organic phase in the extraction equipment. Mixer-settlers are widely used in the chemical process industry because of reliability, operating flexibility, and high capacity. These extractors are particularly economical for operations that require few stages. In this process, 5-9 stages are needed (see Sections 4.3.1 and 4.4.1). Taking into account the time or reaction ( $5 \mathrm{~min})$, phase ratio $(\mathrm{AP} / \mathrm{OP}=5$ and $\mathrm{OP} / \mathrm{SP}=5)$ and total throughput $\left(<2.5 \mathrm{~m}^{3} / \mathrm{h}\right)$, vertical agitated mixer-settler are recommended [30].

A mixer-settler cascade was chosen as extraction equipment.

\subsubsection{Number of Stages}

The number of stages has been determined graphically from the McCabe-Thiele diagram that represents the equilibrium curve and the operating line. The equilibrium curve consists of a series of experimental points, which represents the germanium content in raffinate and the Ge content in the organic extract for different volumetric ratios (AP/OP) and residence times. After contact, both phases are in equilibrium. The operating line sets the operating conditions and its slope is the ratio AP/OP.

The graphical representation of the McCabe-Thiele diagram of this system is shown in Figure 3 [21]. Three theoretical stages are required, and the extraction yield achieved is $98 \%$.

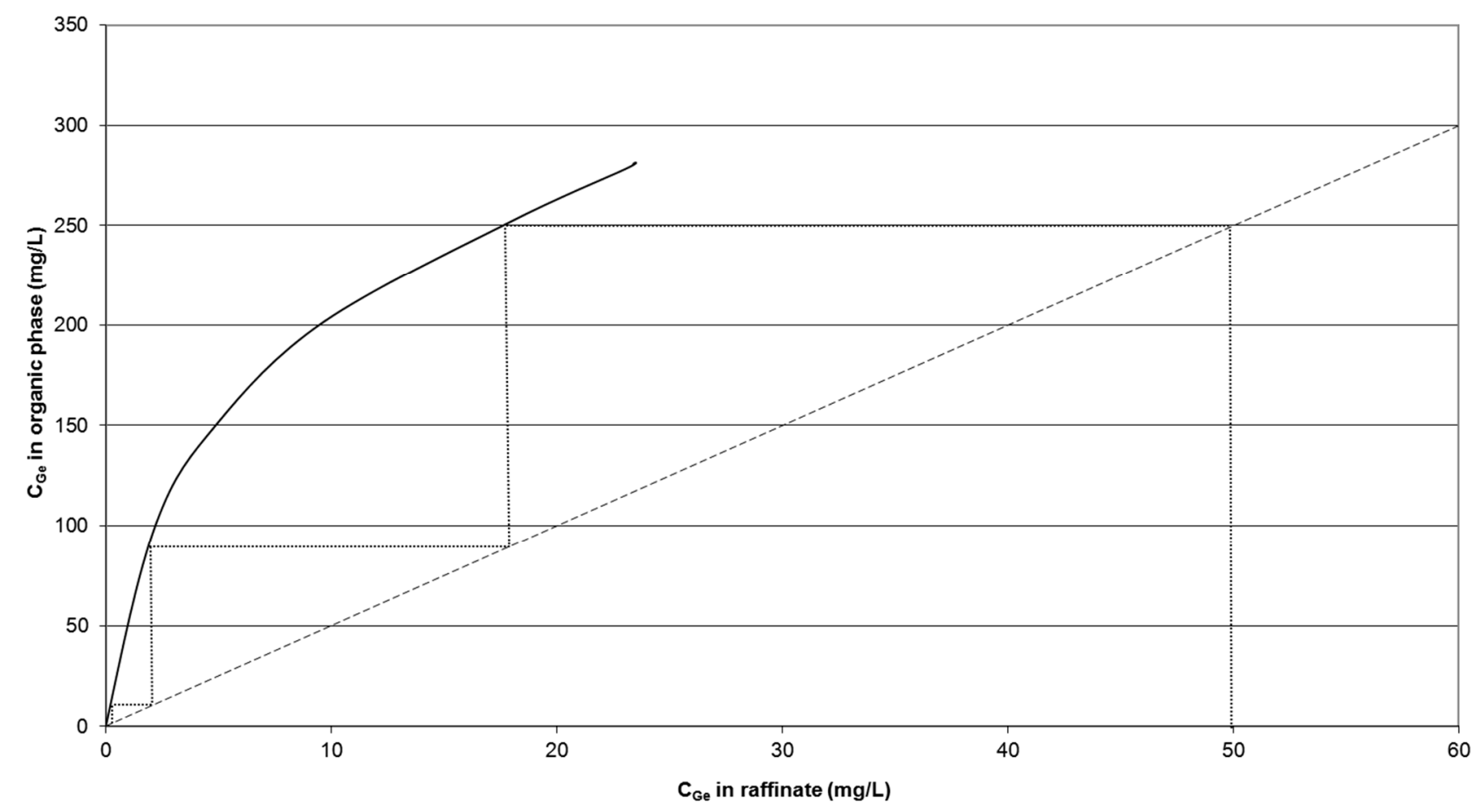

Figure 3. McCabe-Thiele diagram of extraction system.

According to Cox and Musikas [31], the number of real stages should be the theoretical number multiplied by $1.5-2$. So, the real number of extraction stages should be five. 


\subsubsection{Mixer Geometry}

The extraction equipment consists of a mixing chamber, where phases are contacted in counter-current and are mixed by the effect of agitation, and the settler consists of a settling chamber, where the phases are separated. Each extraction stage comprises one mixer and one settler.

The extraction mixer is made up of vertical cylindrical equipment with a tori-spherical bottom head constructed of stainless steel AISI 316, similar to the leaching reactor but with different size. Taking into account the flows of the aqueous and organic phases (Table 2), the residence time (5 min) and the filling factor (80\%) according to results obtained in pilot plant tests [21,22], the volume in the mixer is $0.113 \mathrm{~m}^{3}$ (Equation (3)) and the diameter and height of the mixer have both been determined as $480 \mathrm{~mm}$ (Equation (4)). Four baffles have been distributed along the perimeter of the tank (cross form): $b_{w}=48 \mathrm{~mm}, b_{c}=8 \mathrm{~mm}$ and $b_{a}=24 \mathrm{~mm}$ (Equations (5)-(7)).

According to previous considerations, the geometry of the turbine agitator was $d_{\text {imp }}=h_{\text {imp }}=160 \mathrm{~mm}$, and $l_{\text {blades }}=40 \mathrm{~mm}$ (Equations (8)-(10). The $N_{\max }$ recommended for this agitator was $120 \mathrm{r} \cdot \mathrm{min}^{-1}$ (Equation (11)) and the calculated power is $0.02 \mathrm{~kW}$.

\subsubsection{Settler Geometry}

The settler is a parallelepiped constructed of stainless steel AISI 316. The most important aspect of this settler is the total separation of the phases, which is difficult since the ratio AP/OP is very large and OP occupies a small fraction of the volume settler. The most important design parameter of the sediment in this regard is the specific flow, which is defined as the flow per horizontal area.

In pilot plant tests, several problems with the original settler design were observed. Settling times around $15 \mathrm{~min}$ were needed for a complete phase separation. For typical Q/A ranging $0.06-0.1 \mathrm{~m}^{3} / \mathrm{m}^{2} \cdot \min$ [25], settler lengths from 0.9 to $1.5 \mathrm{~m}$ were needed. In Table 4, different widths of settler are shown. A preliminary estimate of settler length is $1500 \mathrm{~mm}$ to ensure complete phase separation. The flow to the settler is $0.987 \mathrm{~m}^{3} / \mathrm{h}$. It is not recommended to exceed the maximum specific flow, so it will take an operational ratio Q/A of $4.8 \mathrm{~m}^{3} / \mathrm{m}^{2} \cdot \mathrm{h}$. The minimum height of the settler is $100 \mathrm{~mm}$ for easy separation of the phases. Therefore, the settler dimensions are: $1500 \mathrm{~mm}$ (length), $1100 \mathrm{~mm}$ (height) and $140 \mathrm{~mm}$ (width).

Table 4. Different options for settler design: widths, ratio $\mathrm{Q} / \mathrm{A}\left(\mathrm{m}^{3} / \mathrm{m}^{2} \cdot \mathrm{h}\right)$ and settling areas.

\begin{tabular}{cccccccc}
\hline Settler Design Parameters & \multicolumn{7}{c}{ Options } \\
\hline $\mathrm{Q} / \mathrm{A}\left(\mathrm{m}^{3} / \mathrm{m}^{2} \cdot \mathrm{h}\right)$ & 3.6 & 4.0 & 4.4 & 4.8 & 5.2 & 5.6 & 6.0 \\
$\mathrm{~A}\left(\mathrm{~m}^{2}\right)$ & 0.27 & 0.25 & 0.22 & 0.21 & 0.19 & 0.18 & 0.16 \\
$\mathrm{~W}(\mathrm{~m})$ & 0.18 & 0.16 & 0.15 & 0.14 & 0.13 & 0.12 & 0.11 \\
\hline
\end{tabular}

\subsection{Stripping Equipment}

\subsubsection{Number of Stages}

The graphical representation of the McCabe-Thiele diagram of the stripping system is shown in Figure 4 (data from $[21,22]$ ). The theoretical number of required stages is six, and the stripping yield 
achieved is $96 \%$. According to Cox and Musikas [31], the number of real stages should be the theoretical number multiplied by $1.5-2$. Thus, the real number of stripping stages should be nine.

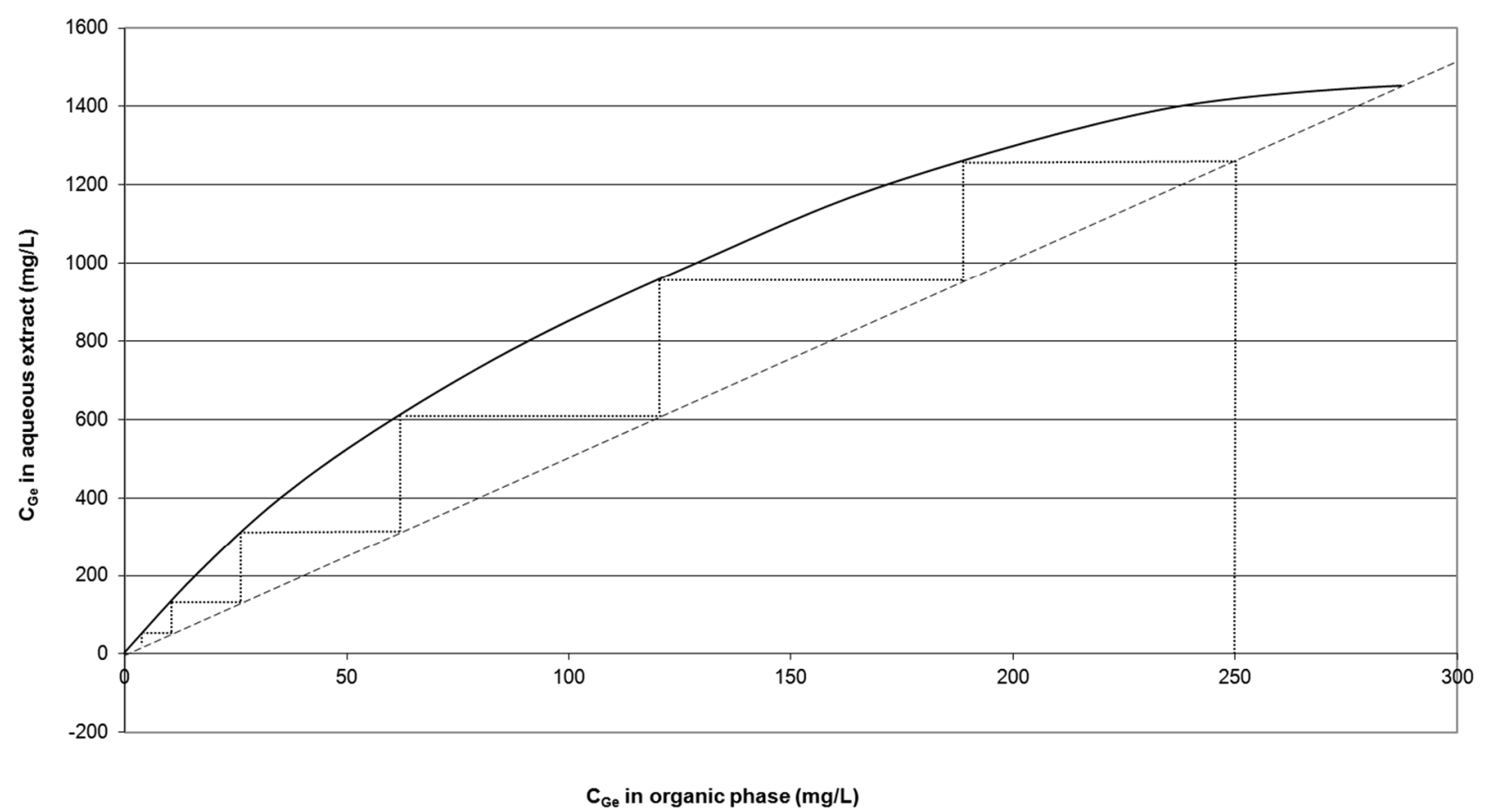

Figure 4. McCabe-Thiele diagram of stripping system.

The stripping system chosen is the same as for the extraction equipment. The flow arrangement is counter-current.

\subsubsection{Mixer Geometry}

The SP and OP are in a vertical cylindrical mixer with a tori-spherical bottom constructed of stainless steel AISI 316 (similar to leaching and extraction mixer reactors). For a phase volume ratio of $5[13,14]$, the residence time in the stripping mixer (5 min [14]) and the filling factor (80\%), the volume of the reactor is $0.023 \mathrm{~m}^{3}$.

According to the equations considered in the design of the extraction mixer (Equations (3)-(11), the stripping mixer is: $D=300 \mathrm{~mm}$ and $H=200 \mathrm{~mm}$ high with four baffles made of the same stainless steel AISI 316, distributed along the perimeter. A six flat-blade turbine agitator is designed with the following geometry: $b_{w}=30 \mathrm{~mm}, b_{c}=5 \mathrm{~mm}$ and $b_{a}=15 \mathrm{~mm}, d_{\text {imp }}=100 \mathrm{~mm}, h_{\text {imp }}=70 \mathrm{~mm}$ and $l_{\text {blades }}=25 \mathrm{~mm}$. The $N_{\max }$ allowed for this agitator is $195 \mathrm{r} \cdot \mathrm{min}^{-1}$ and the power consumed by the agitator reaches $0.02 \mathrm{~kW}$.

\subsubsection{Settler Geometry}

The settler is a parallelepiped constructed of stainless steel AISI 316. In the stripping stage, phases are easily separated [21], so a settling time of around $6 \mathrm{~min}$ was enough to ensure phases separation. Taking into account the same considerations as for the extraction settler, for a flow of $0.2 \mathrm{~m}^{3} / \mathrm{h}$ and $\mathrm{Q} / \mathrm{A}=3.6 \mathrm{~m}^{3} / \mathrm{m}^{2} \cdot \mathrm{h}$, the settler dimensions are: $400 \mathrm{~mm}$ (length), $280 \mathrm{~mm}$ (height) and $78 \mathrm{~mm}$ (width). 


\section{Demonstration Plant Scheme}

In Figure 5, a basic scheme of the process is shown. Fly ash is stored (S1) from where it is fed into the leaching reactor (R1) through the conveyor T1. The feed flow is $200 \mathrm{~kg} / \mathrm{h}$ of FA.

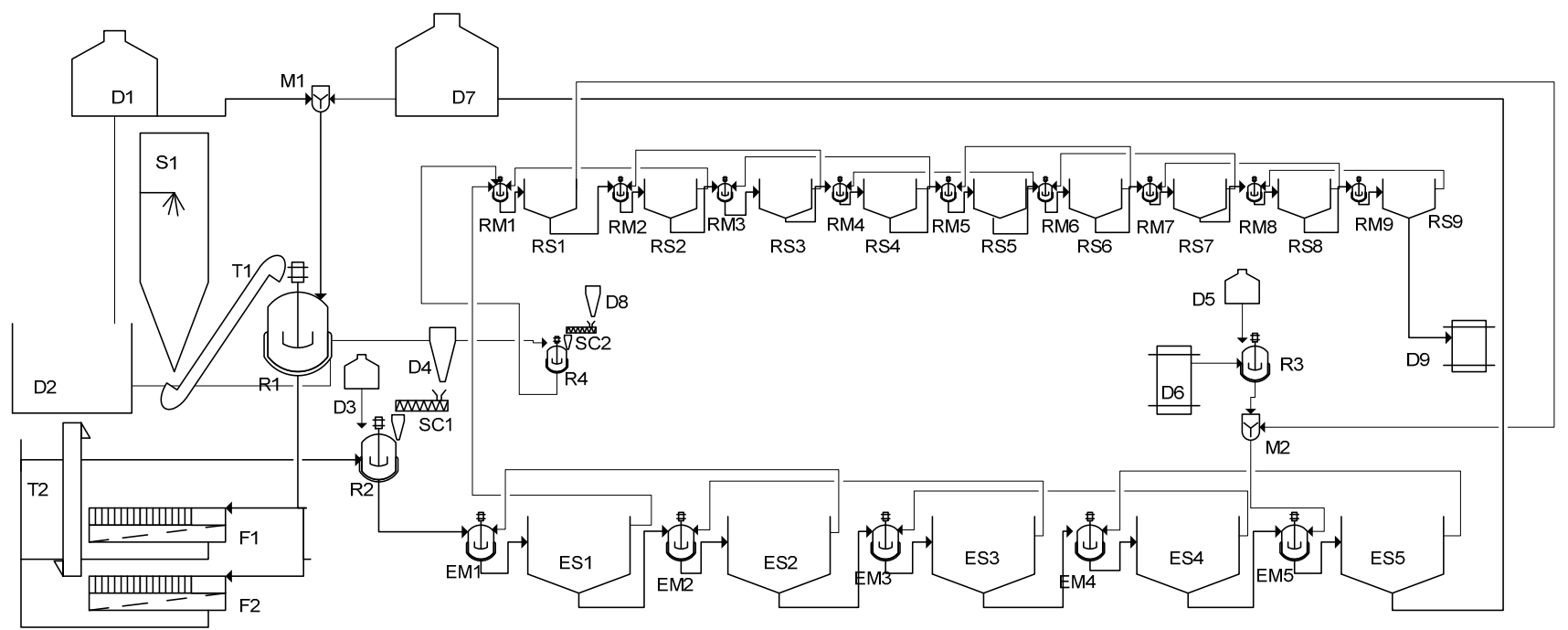

Figure 5. Demonstration plant scheme.

The plant has a water storage tank D1 for a day of plant operation in case of failure. Most of the leaching solution quantity is reintroduced from the process (raffinate from solvent extraction stage).

The slurry from the leaching reactor R1 is pumped to one of the filter press (F1 or F2). Two press filters have been installed so that one can filter while the other is discharged and cleaned. Wet fly ash with 35\% moisture (approx.) is stored until reutilization (D2).

Leachate collected from the filter is pumped to the mixer (R2) where extracting solution is prepared by addition of catechol and sulfuric acid. CAT is stored in solid state (D4) and transported to the R2 with a screw ( $\mathrm{SC} 1$ ). Sulfuric acid is stored in the tank D3 and pumped to $\mathrm{R} 2$. The OP prepared in the reactor R3 consists of kerosene and trioctylamine. Kerosene is stored in D6 and pumped to R3. Similarly, TOA is stored in D5 and pumped to R3.

The AP and OP are introduced in the first and last stages of SX equipment respectively. Each stage is made up of a mixer-settler (ER1-ER5/SR1-SR5).

Raffinate is stored in the tank D7 until its reintroduction in the R1 (leaching stage).

The pregnant OP is introduced in stripping equipment, where it is in contact with sodium hydroxide $3 \mathrm{M}$ coming from $\mathrm{R} 4$, which receive sodium hydroxide in solid form from the silo D8 and tank water D1. The stripping equipment is named RE1-RE9/RS1-RS9.

After stripping, the pregnant and concentrated solution of germanium is stored in the tank D9 designed for that purpose. The organic waste is stored in D10 until the returned to the extraction stage.

\section{Cost Estimation}

This section provides factored cost estimation (Lang methodology) based on the ratio of main plant equipment (mixers and settlers). This estimate has an accuracy of 30\%. The Lang methodology for cost estimation consists of two steps: 
Step 1: Estimated cost of main equipment. The total cost of main equipment is the sum of the estimated costs of main individual equipment (Table 5).

Table 5. Factors for global investment estimation.

\begin{tabular}{cc}
\hline Equipment & Cost $(\boldsymbol{\epsilon})$ \\
\hline Extraction equipment & - \\
Mixers & 75,000 \\
Settlers & 25,000 \\
Stripping equipment & - \\
Mixers & 70,000 \\
Settlers & 30,000 \\
Auxiliary reactors & 50,000 \\
Pumps & 30,000 \\
Liquid store & 70,000 \\
Total & 360,000 \\
\hline
\end{tabular}

Step 2: Corrections. The cost calculated in Step 1 has to be corrected to consider additional costs such as direct and indirect costs. This correction factor is called a global factor of Lang and it is a function of the type of plant. The global cost can be calculated as shown in Equation (18) [32].

$$
I_{\text {TOTAL }}=\left(I_{b}\right) \cdot\left(\Sigma f_{\text {dir }} \cdot f_{\text {Ind }} \cdot f_{\text {fix }}\right)=F_{\text {Lang }} \cdot I_{b}
$$

Where $I_{\text {total }}$ is the total investment, $F_{\text {lang }}$ is the Lang factor and $I_{\mathrm{b}}$ is the total cost of main equipment, $f_{\text {dir }}$ includes the factors to estimate direct costs and find includes the factors to estimate indirect costs (Table 5).

The estimated investment for the demonstration plant implantation is: $375,000 \times 4.8=1,800,000 €$.

\section{Conclusions}

The conceptual process design of a demonstration plant has been performed, including the evaluation of process, the identification of equipment options and early investment analysis.

The mass balance of the demonstration plant $(200 \mathrm{~kg} / \mathrm{h})$ has been performed using the experimental results obtained at pilot plant scale $(5 \mathrm{~kg} / \mathrm{h})$.

Main equipment (leaching reactor, filters, and extraction and stripping equipment were designed and data for the preliminary design was obtained in tests at laboratory and pilot plant scale.

Almost $61 \mathrm{~g} / \mathrm{h}$ of $\mathrm{GeO}_{2}$ (equivalent) could be recovered from a $200 \mathrm{~kg} / \mathrm{h}$ of industrial residue such as fly ash.

The estimated investment for the demonstration plant (direct and indirect costs) is 1,800,000 euros.

\section{Author Contributions}

Fátima Arroyo performed some calculations and wrote the paper, Constantino Fernández-Pereira revised the paper, and Pilar Bermejo performed some of the calculations. 


\section{Conflicts of Interest}

The authors declare no conflict of interest.

\section{References and Notes}

1. Adams, J.H.; Thomas, D. Germanium and germanium compounds. In Ullman's Encyclopedia of Industrial Chemistry; Wiley-VCH Verlag GmbH: New York, NY, USA, 2000.

2. MetalPrices. Available online: http://www.metalprices.com (accessed on 26 May 2015).

3. Querol, X.; Fernández-Turiel, J.L.; López-Soler, A. Trace elements in coal and their behaviour during coal combustion in a large power station. Fuel 1995, 74, 331-343.

4. Font, O.; Querol, X.; Huggins, F.; Chimenos, J.M.; Fernández, A.I.; Burgos, S.; García Peña, F. Speciation of major and selected trace elements in IGCC fly ash. Fuel 2005, 84, 1364-1371.

5. Font, O.; Querol, X.; Lopez-Soler, A.; Chimenos, J.M.; Fernandez, A.I.; Burgos, S.; Garcia Pena, F. Ge extraction from gasification fly ash. Fuel 2005, 84, 1384-1392.

6. Font, O.; Querol, X.; Plana, F.; Coca, P.; Burgos, S.; Pena, F.G. Condensing species from flue gas in Puertollano gasification power plant, Spain. Fuel 2006, 85, 2229-2242.

7. Font, O.; Querol, X.; Juan, R.; Casado, R.; Ruiz, C.R.; López-Soler, A.; Coca, P.; García Peña, F. Recovery of gallium and vanadium from gasification fly ash. J. Hazard. Mater. 2007, 139, 413-423.

8. Font, O. Trace Elements in Integrated Gasification Combiner Fly Ash: Extraction of Potential Valuable Elements. Ph.D. Thesis, Universitat Politècnica de Catalunya, Barcelona, Spain, 2007.

9. Jandova, J.; Vu, H. Recovery of Germanium-Bearing Fly Ash. In Metallurgy, Refractories and Environment; Technical University of Košice: Košice, Slovakia, 2001; pp. 107-112.

10. Matis, K.A.; Mavros, P. Recovery of Metals by Ion Flotation from Dilute Aqueous Solutions. Sep. Purif. Rev. 1991, 20, 1-48.

11. Hernández-Expósito, A.; Chimenos, J.M.; Fernández, A.I.; Font, O.; Querol, X.; Coca, P.; García Peña, F. Ion flotation of germanium from fly ash aqueous leachates. Chem. Eng. J. 2006, 118, 69-75.

12. Marco-Lozar, J.P.; Cazorla-Amorós, D.; Linares-Solano, A. A new strategy for germanium adsorption on activated carbon by complex formation. Carbon 2007, 45, 2519-2528.

13. Arroyo, F.; Fernández-Pereira, C.; Querol, X.; Font, O.; Coca, P.; Chimenos, J.M.; Fernández, A.I. Method for the Recovery of Germanium Present in Coal Ash. Patent WO/2008/003808, 10 January 2008.

14. Arroyo, F.; Fernandez-Pereira, C. Hydrometallurgical recovery of germanium from coal gasification fly ash, solvent extraction method. Ind. Eng. Chem. Res. 2008, 47, 3186-3191.

15. Menendez, F.J.S.; Menendez, F.M.S.; de La Cuadra Herrera, A.; Tamargo, F.A.; Valcárcel, M.R.; Fernandez, V.A. Process for the Recovery of Germanium from Solutions that Contain It. US Patent 4,886,648, 29 June 1989.

16. Harada, A.; Tarutani, T.; Yoshimura, K. Spectrophotometric determination of germanium in rocks after selective adsorption on Sephadex gel. Anal. Chim. Acta 1998, 209, 333-336.

17. Arroyo Torralvo, F.; Fernández-Pereira, C. Recovery of germanium form fly ash leachate by ion-exchange extraction. Miner. Eng. 2011, 24, 35-41. 
18. Moskalyk, R.R. Review of germanium processing worldwide. Miner. Eng. 2004, 17, 393-402.

19. Arroyo Torralvo, F.; Font, O.; Pereira Fernandez, C.; Querol, X.; Juan, R. Germanium recovery from gasification fly ash: Evaluation of end-products. J. Hazard. Mater. 2009, 167, 582-588.

20. Arroyo Torralvo, F.; Fernandez-Pereira, C.; Coca, P. Precipitación of germanium from coal fly ash leachates. Coal Combust. Gasif. Prod. 2010, 2, 28-34.

21. Arroyo Torralvo, F. Recuperación del Germanio Presente en la Ceniza Volante Producida en Una Planta GICC que Emplea Carbones de la Cuenca de Encasur en Puertollano. Ph.D. Thesis, University of Seville, Seville, Spain, 2008. (In Spanish)

22. Arroyo, F.; Fernández-Pereira, C.; Olivares, J.; Coca, P. Hydrometallurgical Recovery of Germanium from Coal Gasification Fly Ash: Pilot Plant Scale Evaluation. Ind. Eng. Chem. Res. 2009, 48, 3573-3579.

23. Palluzi, R.P. Pilot plants. In Ullman's Encyclopedia of Industrial Chemistry; Wiley-VCH Verlag GmbH: New York, NY, USA, 2005.

24. Crittenden, J.C.; Trussell, R.; Hand, D.W.; Howe, K.J.; Tchobanoglous, G. Principles of Reactor Analysis and Mixing. In MWH's Water Treatment: Principles and Design, 3rd ed.; John Wiley \& Sons: Hoboken, NJ, USA.

25. Perry, R.H.; Green, D.W. Perry's Chemical Engineers' Handbook, 7th ed.; McGraw-Hill: New York, NY, USA, 1997.

26. Thakur, R.K.; Vial, C.; Djelveh, G.; Labbafi, M. Mixing of complex fluids with flat-bladed impellers: Effect of impeller geometry and highly shear-thinning behavior. Chem. Eng. Process. 2004, 43, 1211-1222.

27. Wei, J.; Anderson, J.L.; Bischoff, K.B. Advances in Chemical Engineering; Academic Press: Waltham, MA, USA, 1991; Volume 17.

28. Al-Khafaji, A.A.A.R. Prediction of Filter Life by Measurement of Cake Resistance. Ph.D. Thesis, Iowa State University: Ames, IA, USA, 1967.

29. Sincero, A.P.; Sincero, G.A. Environmental Engineering. A Design Approach; Prentice Hall: Upper Saddle River, NJ, USA, 1996.

30. Stevens, G.W.; The, C.L.; Malcolm, H.B. Extraction, Liquid-Liquid. In Kirk-Othmer Encyclopedia of Chemical Technology; John Wiley and Sons: Hoboken, NJ, USA, 2007.

31. Cox, M.; Musikas, C. Solvent Extraction Principles and Practice; CRC Press: Boca Raton, FL, USA, 2004.

32. Plant Design and Economics for Chemical Engineers. Max S. Peters, University of Colorado, Klaus Timmerhaus, University of Colorado, Boulder, Ronald E. West, University of Colorado, Boulder. Available online: http://highered.mheducation.com/sites/0072392665/student_view0/ index.html (accessed on 22 May 2015).

(C) 2015 by the authors; licensee MDPI, Basel, Switzerland. This article is an open access article distributed under the terms and conditions of the Creative Commons Attribution license (http://creativecommons.org/licenses/by/4.0/). 